Historic, Archive Document

Do not assume content reflects current scientific knowledge, policies, or practices. 

Resure

A 423.9

P 31
ARS 81-9-1

November 1963

U. S. DEPT. OF RGRICULTURE

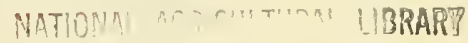

\section{MAK 201964}

IMPORTED

FIRE ANT

)

PROGRAM AND PROGRESS

Agricultural Research Service UNITED STATES DEPARTMENT OF AGRICULTURE 
Fire Ant History in USA ........................................................... 1

Cooperative State-Federal Program .............................................. 2

Financing The Program................................................................. 2

Program Development................................................................. 3

Improvements Made...................................................................... 3

Goals Established......................................................................... 4

Procedures ................................................................................ 4

Surveys.................................................................................. 4

Quarantines ............................................................................... 5

Treatment .............................................................................. 5

Safety Stressed ...................................................................... 5

Public Health....................................................................................... 6

Pesticides And Wildlife ................................................................ 6

Progress So Far ....................................................................... 6

Economic Damage--Indirect...................................................... 6

Economic Damage--Direct...................................................... 7

A City Pest Too ............................................................................. 7

Fire Ant Stings .................................................................... 8

Life of the Imported Fire Ant ................................................... 8

Mounds ......................................................................................... 9

Your Stake in the Imported Fire Ant Program .................................. 9

Summary Guidelines ........................................................................ 10

The mention of commercial products in this publication does not constitute an endorsement by the U.S. Department of Agriculture over other products not mentioned.

Prepared from information supplied by

Plant Pest Control Division

Agricultural Research Service United States Department of Agriculture 


\section{THE IMPORTED FIRE ANT}

\section{Program and Progress}

The imported fire ant is an annoying and destructive pest in the South that:

- Builds mounds, which interfere with crop production and mar the landscape.

- Attacks and sometimes kills plants, young animals, and birds.

- Has a painful sting capable of causing serious illness to persons allergic to the venom.

- Is difficult and costly to control on an individual basis.

The imported fire ant has been found in Alabama, Arkansas, Florida, Georgia, Louisiana, Mississippi, North Carolina, South Carolina, and Texas. It is known to infest millions of acres in 277 counties in these States.

The main body of the infestation lies within an arc extending from southeastern Texas to northern Mississippi and Alabama, western Georgia, and northwestern Florida.

\section{FIRE ANT HISTORY IN USA}

The imported fire ant entered this country at Mobile, Ala., around 1918. However, because it closely resembles native fire ants, it was not identified as a separate species until 1930.

From Mobile, it began to spread outward, and by 1937, was a serious pest. That year the State of Alabama made the first full-scale effort to control the ant. The ants appeared to die down for a time, but by 1947 they had spread to a number of areas in Alabama and Mississippi. Mississippi initiated a limited control program in 1948.

The pest continued to spread and by the end of 1953 it was known to infest 102 counties in 9 States. By the beginning of 1957, the ants were present in more than 170 counties and many people were getting alarmed about this spreading menace. The USDA began receiving communications from property owners, organizations, and Representatives of Congress urging consideration of a program that would give relief from these vicious insects.

That the seriousness of the problem was recognized is shown by the following events that occurred in 1957:

ITEM: On March 11-12, the Southern Plant Board, representing 10 Southern States, met in Mobile, Ala., and adopted a resolution recommending that immediate steps be taken to initiate a joint Federal-State-local program leading to the eventual eradication of the imported fire ant. The following month, the Board held a special session in Birmingham, Ala., to develop a plan to accomplish this purpose.

ITEM: On June 4, the Executive Committee of the National Association of Commissioners, Secretaries, and Directors of Agriculture adopted a resolution supporting the action of the 
Plant Board and directed that copies of the resolution be sent to the chairman of the Subcommittee on Agriculture in the Senate Agriculture Committee and to the Agricultural Research Service.

ITEM: On June 7-10, the Southern Association of State Commissioners of Agriculture, meeting in Biloxi, Miss., passed a resolution "recognizing the imported fire ant as an economic pest preying on livestock, pastures, forests, wildlife, small grain, and of great importance to human life, and that it is important and necessary that all divisions of local, State, and national governments unite in a concentrated effort for its immediate control and eradication." The resolution added: "We do hereby petition Congress now in session to provide sufficient funds to the USDA in order that they might carry out their part of the uniform program without delay."

As a result of these and other similar resolutions, plus pleas for relief from individuals, appropriate committees of Congress made a careful review of the imported fire ant situation in the South, and in the fall of 1957, Congress authorized the USDA to join interested States in an eradication program.

\section{COOPERATIVE STATE-FEDERAL PROGRAM}

Since 1957, the U.S. Department of Agriculture has cooperated with interested States in an intensive attack on the imported fire ant.

The program is conducted jointly by the Plant Pest Control Division of USDA'S Agricultural Research Service and State plant pest control agencies and institutions, local governments, organizations, and property owners.

In addition, most States with imported fire ants have established fire ant advisory committees--usually at State and local levels. The State committee works with program officials in developing plans and conducting the fire ant program under State and Federal supervision.

Farmers and other residents may participate through local committees in deciding how local support--cash, materials, or labor--is to be obtained. The local committees also represent property owners--inorganizing and carryingout the program in cooperation with Federal and State officials.

Other groups actively participating in the program include:

- State and county highway commissions.

- Railroad, truck, and air transport companies.

- Public health agencies.

- Utility companies.

- School boards, nurseries, playground supervisors.

- Managers of recreational areas.

\section{FINANCING THE PROGRAM}

In 1957, for the first time, Congress provided funds for the Department to assist affected States in undertaking an imported fire ant program. Since that time Congress has continued to appropriate money to supplement funds provided by State and local sources. 
Federal funds are used: To administer the Federal quarantine; to conduct surveys to detect presence of the ant and to determine the limits of the infestations; to develop more efficient and economical means of eradication; and to participate with State and local agencies, organized groups of property owners, and utility companies in eradicating the fire ant.

State participation may consist of appropriations alone, or it may be a combination of State and county appropriations and cost-sharing by landowners.

The support of farmers and others under this system has been impressive--particularly in areas heavily infested with the imported fire ant. Requests for assistance in controlling the ants have consistently exceeded money available.

\section{PROGRAM DEVELOPMENT}

At the start of the program, a Methods Improvement Laboratory was established at Gulfport, Miss., to improve effectiveness and economy of operations.

Program improvements reflect the pertinent studies made by this team, as well as studies carried out cooperatively with USDA and State experiment stations, and State and Federal fish and wildlife agencies, and observations of Federal and State field personnel.

\section{IMPROVEMENTS MADE}

Much progress has been made in developing more effective methods of combatting this insect. At the start of the program, the standard treatment was a single application of 2 pounds of heptachlor per acre. By tightening specifications and working with insecticide producers to obtain more uniform formulations, Methods Improvement scientists were soon able to reduce the amount of insecticide required to $1-1 / 4$ pounds per acre. Further work demonstrated that effective results could be obtained with two applications of $1 / 4$ pound each of heptachlor at intervals of 3 to 6 months apart.

However, the biggest breakthrough in the program came in 1961, with the discovery of an effective formulation called Mirex bait. For years, USDA scientists had performed hundreds of tests with various attractants, toxicants, and granular carriers. Finally, they found the right combination with the insecticide, Mirex--soybean oil and ground corncob grits.

This bait is made in two formulations: One containing 0.15 percent Mirex, applied at 5 pounds per acre; and the other containing 0.075 percent Mirex, applied at 10 pounds per acre. Each formulation deposits 3.4 grams, or less than $1 / 7$ ounce, of the toxicant uniformly distributed on each acre.

The advantages of Mirex are: It can be used on all infested land without the necessity of "flagging-out" sensitive areas such as pastures and ponds; it can be applied under less critical weather conditions than contact insecticides because the ants seek it for food; it has no harmful effect on people, domestic animals, fish and wildlife, or bees; and it leaves no harmful residue in milk, meat, or crops. 
Still another favorable feature is its delayed toxic action on the ants. This delay allows the foraging ants time to carry the bait into their colony and distribute it to the queen and larvae before it starts taking effect. If it killed some of the ants quickly, the others would become suspicious and leave the area before getting a fatal dose of the insecticide.

It should be noted that single treatments with Mirex bait may not eradicate fire ants if applied during or shortly after mating flights. The reasons for this is that newly mated queens do not forage and since Mirex bait leaves no residue, it will not kill queen ants in the process of forming new colonies. It is believed that precise timing of application will make it possible to eradicate the ants with a single treatment. Otherwise, a second application may be necessary.

Meanwhile, the search for ever more effective baits and methods is continuing.

Heptachlor, an effective and economical material, will still be used in some situations. These include: outlying infestations beyond the periphery of the generally infested area; nurseries and transportation sites which could involve spreading of infestations; barriers, to protect baited areas against reinfestation; airports; and road shoulders in heavily infested areas that present a serious hazard of spread through the movement of road maintenance equipment and motor vehicles.

When heptachlor is used, it is mixed with a special clay and applied in a dry, granular form that sifts readily through foliage. When the granules reach the ground, moisture breaks them down and the insecticide is released. It kills ants on contact. Heptachlor is applied with ground equipment, either mechanical or manual.

\section{GOALS ESTABLISHED}

In order to accomplish ultimate eradication, the following goais were established:

1. Surveys to determine the location of the ants.

2. Quarantine regulations to prevent the ants from invading additional States and regions.

3. Eradication of outlying infestations first to shrink the periphery of the total region having ants.

4. Suppression of ant populations within a generally infested area so that uninfested land is protected.

\section{PROCEDURES}

Three coordinated steps to eradicate the imported fire ant now being carried out are: (1) Surveys, (2) quarantines, and (3) treatment.

Surveys

Surveys are conducted by Federal and State pest control workers to determine the outer limits of the generally infested areas, and the extent and degree of infestation. Such 
information permits program officials, with the aid of advisory committees and other Federal-State agencies, to plan effective program procedures to combat the pest.

Surveys are continuous because of the ever-changing pattern of infestation. However, efforts to spot new infestations are intensified in the fall and winter months when mounds are less obscured by vegetation.

Quarantines

A Federal quarantine was invoked in 1958 to help prevent the interstate spread of the imported fire ant and to protect treated areas from reinfestation.

The Federal quarantine and parallel State Quarantines regulate the movement of materials such as soil, gravel, and sand, or products with soil attached; and unmanufactured forest products.

By inspecting these products, and treating them if necessary, State and Federal program personnel have kept them moving in trade channels in compliance with Federal and State quarantine regulations. Long-distance spread of the pest through commerce has thus been prevented.

States immediately affected by quarantines are: Alabama, Arkansas, Florida, Georgia, Louisiana, Mississippi, North Carolina, South Carolina, and Texas.

\section{Treatment}

Properly used insecticides are the only practical means of ridding an area of imported fire ants. Insecticides are applied by aircraft, motorized ground machinery, and hand applicators.

Each area is studied to determine the proper method and timing for the application.

Aircraft are used to treat large, generally infested, open areas, and places not easily reached by other equipment.

Ground equipment, motorized and hand, is used to treat small blocks in easily accessible places or to retreat occasional mounds that reappear.

Sometimes various combinations of aircraft and other methods are used.

Isolated infestations beyond the boundary of the generally infested areas are treated first to shrink the outer edge of the infestations.

\section{SAFETY STRESSED}

Close Federal or State supervision of eradication activities is maintained at all times. When airplanes are used, the application is supervised from the air by USDA pilots or trained 
supervisors while ground crews mark the swath widths with special balloons. Radio communication insures that operations are coordinated. Planes applying insecticide over congested areas must undergo rigid inspection by the Federal Aviation Agency.

\section{PUBLIC HEALTH}

The Federal Pest Control Review Board, established to review Federal pest control programs and to insure that the most effective, economical, and safe pest control procedures are followed, approved the 1963 imported fire ant program. Dr. Robert J. Anderson, M.D., of the Public Health Service is chairman of the review board which includes representatives of the Departments of Agriculture, Defense, Interior, and Health, Education, and Welfare.

Insecticides used in this program have been screened by USDA and the Department of Health, Education, and Welfare for safety of persons applying the insecticide as well as for the health of people living in the areas being treated.

\section{PESTICIDES AND WILDLIFE}

From the beginning, the U.S. Department and State officials have been concerned about any possible adverse effects of insecticides on wildlife. Despite best efforts, some wildlife was lost in the early days of the program. However, wildlife losses were temporary and never extensive. Even these slight hazards were removed when the dosage of heptachlor was reduced to split applications of $1 / 4$ pound per acre. No adverse effects of any kind has been noted on wildlife on thousands of acres treated with Mirex bait.

\section{PROGRESS SO FAR}

The following progress in the imported fire ant program has been made:

- More than 4,400,000 acres have been treated with insecticide.

- Treatments have been made in more than half of the 277 counties known to be infested.

- Treatments in Arkansas, North Carolina, and South Carolina are in the "cleanup" stage.

- Federal quarantine regulations have prevented long-distance, artificial spread of the ant without restricting the sale of regulated commodities.

- Development of an effective bait has removed most objections to the program.

\section{ECONOMIC DAMAGE--INDIRECT}

Imported fire ants are destructive, costly pests. However, greatest losses from the fire ants come from the reduced efficiency of land used and labor and machinery--losses hard to assess in dollar values. 
Unfortunately for the farmer, ants prefer land exposed to the sun. Therefore, some of the most valuable farming and pasture land is most heavily infested. Improved pastures and hay fields are especially hard hit.

Whenever land is cultivated only intermittently, as in improved pastures, ants increase rapidly. This is an important factor in areas where livestock production represents a vital part of the agricultural economy.

The total time farmers lose during seeding, fertilizing, or harvesting is difficult to estimate. But with 20 to 40 ant mounds per acre--not uncommon in heavily infested areas--the difficulties can be great.

For example, when hay is cut and left to dry in an infested field, the imported fire ants build mounds in the fallen hay. The ants delay the farmer in getting his hay into storage and the hay is often damaged by weather, In addition, when the hay is baled, soil from the mounds is gathered up in the hay, making that part unpalatable to livestock--therefore worthless.

The ants can also complicate the harvesting of small grains. It is practically impossible for the farmer to cut grain-growing over or near fire ant mounds. If he does cut such grain, he risks expensive breakdowns to his machinery. If he uses combines, soil from mounds gets into the machinery and grain.

All in all, the ants cause damaged equipment, loss of time and labor, loss of grain, and lower prices for grain containing soil.

In addition, it's difficult to hire workers to harvest crops or cultivate fields in heavily infested areas--which may contain as many as 10 million worker ants per acre.

\section{ECONOMIC DAMAGE--DIRECT}

Imported fire ants also cause direct damage--although this is probably not so serious as their indirect damage.

They sometimes damage vegetable crops, such as okra, collard, cabbage, egg plant, germinating seed corn, and citrus trees. They soften the tender stems just below the soil, then suck the plant juices; gnaw holes in roots, tubers, stalks, buds, ears, and pods.

Farmers have reported that the ants attack young, unprotected animals, such as newborn calves and pigs and the young of ground-nesting birds.

\section{A CITY PEST, TOO}

Imported fire ants are much more than an agricultural problem. They can make life miserable--and create a health hazard--to city dwellers by invading lawns, cemeteries, parks, playgrounds, school yards, golf courses, and even homes.

The mounds are unsightly and cause inconvenience in caring for grounds. In heavily infested areas, they can make recreational areas and school yards and other places that children might play particularly hazardous. 
Atlanta, Ga., offers a good example of how serious the ants can become in a major city. Although the ants were known to be in the Atlanta area for several years, they did not become a serious health problem until the latter part of 1962 when their population exploded and rapidly spread throughout 600,000 acres. As a result of the rapid population buildup of the stinging, biting ants, the Georgia Department of Agriculture received 3,000 telephone calls in only 15 days from worried parents and property owners.

Prior to the arrival of cold weather and a slowdown in ant activity, numerous persons, including many small children, required medical treatment for fire ant stings. On several occasions individuals attacked by the ants required hospitalization.

A similar situation occurred in Jackson, Miss., before an application of Mirex bait in 1962 eradicated the ants. Also, as late as 1962 a child in Alabama was critically stung by more than 1,000 of the ants which invaded her bedroom in search of food.

\section{FIRE ANT STINGS}

The ants are aggressive and vicious and will bite and sting anything that disturbs their mound. On the attack they sink their jaws into the flesh, bring the abdomen forward and drive the stinger into the skin where they inject a poison. One ant can sting repeatedly. Afterwards, burning and itching occurs, followed by the formation of a white sore or pustule which may leave a permanent scar.

Dr. Rodney Jung of the Tulane University School of Tropical Medicine found that the venom of the imported fire ant is unlike that of other stinging hymenoptera. Persons unusually sensitive to this venom may suffer chest pains, become nauseated, and even lapse into a coma from a single sting. Persons who suffer severely from fire ant stings should be treated immediately for allergic reactions if they are stung.

\section{LIFE OF THE IMPORTED FIRE ANT}

Imported fire ants belong to the same family as bees, wasps, and hornets. The three forms of imported fire ants are: (1) Winged, fertile females (queens); (2) winged, fertile males; (3) worker ants of various sizes. The workers are wingless, sterile females.

Most ants in a well-developed nest are wingless workers. Their color may vary from dark brown to reddish black, and they have an orange colored band at the base of abdomen.

Worker ants vary from one-eighth to one-fourth inch long. Queens are about three-eighths inch long; fertile males are slightly smaller. After mating, largely in the spring, the fertilized queen finds a nesting site, sheds her now useless wings, digs a brood chamber 1 to 4 inches under ground, then plugs the entrance tunnel. She usually lays her first cluster of 10 to 15 eggs the day after mating. This is the start of a new colony. Meanwhile, the winged male--now homeless--dies within a few days after mating.

By the time the first cluster of eggs hatches into larvae ( 8 to 12 days later), the queen has laid a hundred or more eggs.

When the larvae appear, they are helpless, dirty-white grubs. Within 8 to 12 days, the larvae change to pupae which are pale, shiny white, about the same size as the adults. They 
gradually darken and emerge as adult worker ants in 9 to 12 days. The queen cares for the first brood; workers take care of the later broods.

Mounds

Imported fire ant mounds may befound in almost any kind of soil. They are most common in open areas, such as pastures, parks, roadsides, and cultivated fields. But they are also found in rotting logs and around tree trunks, and occasionally under buildings.

A mound starts when workers from the queen's first brood enlarge the underground quarters. The workers of later broods help build a firm mount that is honeycombed with underground passages.

Although its size depends on location and age, the average mound is about 1 foot high and 2 feet across. Most of the honeycombed galleries are built within an inverted cone, the point of which may be 3 feet below the surface. This cone and the aboveground portion of the mound contain most of the colony--about 100,000 ants in an average nest. More than 60 mounds to the acre is fairly common in infested areas.

Entrance holes normally are not in the mound itself. The workers usually leave and enter through tunnels constructed just below the surface with openings at varying distances from the mound itself. Workers make large exit holes in the mound when a winged queen and her mate prepare to leave the mound but promptly close the hole after the flight. When holes are made in the mound by heavy rains or other disturbances, the workers quickly make repairs.

Imported fire ants may seek new locations for various reasons. The fire ant population may become too large and a colony will look for a new and better source of food. They may move because of a disturbance. Then, too, the older and larger a mound becomes, the more difficult it is to maintain so the ants may elect to get a fresh start somewhere else. The worker ants take complete charge of such a move. They carry the eggs, immature ants, and food to their new home.

\section{YOUR STAKE IN THE IMPORTED FIRE ANT PROGRAM}

As an individual, you have a stake in eradicating the imported fire ant.

Federal and State quarantines and treatment around the outer edges of the infestations have prevented long-distance, artificial spread of this pest to States outside the South. However, should these efforts be slackened or abandoned, the ant could continue to move northward and westward to Philadelphia, Pa., Indianapolis, Ind., Denver, Colo,, and southern California.

Individuals can help the program succeed by:

- Reporting suspected infestations to their country agent or State entomologist as soon as possible.

- Participating in community action designed to wipe out the fire ant.

- Giving survey and eradication workers free access to their property.

- Following all precautions recommended when insecticides are applied. 
Based on the accumulation of knowledge and experience, the Plant Pest Control Division believes:

- The imported fire ant can be eradicated.

- People want the pest eradicated as demonstrated by their support of the program with money and services.

- The imported fire ant is a costly pest in terms of inconvenience, reduced efficiency of labor and machinery, and in infested land that can't be utilized fully.

- Direct damages to crops, small animals, and birds are real losses, but these losses are secondary to losses of land and labor efficiency.

- Distribution of bait by aircraft is the most efficient method of staying ahead of the relentless spread of the ants in heavily infested areas.

- A vital step in eradication is to keep down populations of ants in the periphery of the generally infested areas.

- Unless checked, the pest could spread throughout much of the United States. 